\title{
Evidenciação de Passivos Ambientais: um estudo com empresas integrantes do ISE
}

\author{
Bárbara Sampaio de Menezes \\ Unicatólica - Quixadá \\ Brasil \\ Mestrado em Administração e Controladoria (UFC) \\ Amanda Thássya Ferreira Félix Pompeu Arruda \\ UFC \\ Brasil \\ Mestra em Administração e Controladoria (UFC)
}

\author{
Augusto Cézar de Aquino Cabral \\ UFC \\ Brasil \\ Doutorado em Administração (UFMG)
}

Sandra Maria dos Santos

UFC

Brasil

Doutorado em Economia (UFPE)

\section{Maria Naiula Monteiro Pessoa}

UFC

Brasil

Doutorado em Engenharia de Produção (UFSC)

Artigo submetido em: 29/06/2017

Aprovado em: 05/02/2018

\section{RESUMO:}

O estudo objetiva analisar o processo de evidenciação de passivos ambientais de empresas integrantes do Índice de Sustentabilidade Empresarial - ISE. A pesquisa justifica-se por gerar contribuições às áreas da contabilidade ambiental e por demonstrar se as organizações listadas nesse índice estão evidenciando adequadamente os seus passivos ambientais. Realizou-se pesquisa descritiva, de natureza quantitativa, por meio da técnica de análise de conteúdo em dados secundários, nas demonstrações financeiras, relatórios administrativos e notas 
explicativas. A amostra constitui-se de 34 empresas listadas no ISE para os anos de 2012, 2013 e 2014, baseada em dados secundários a partir das Demonstrações Financeiras referentes aos exercícios anteriores a cada ano do ISE, obtidos através do site da BM\&FBOVESPA. Desta forma, foram avaliados o Balanço Patrimonial, as Notas Explicativas e o Relatório da Administração, que segundo a literatura estudada são as maneiras mais empregadas na evidenciação do passivo ambiental pelas companhias. Assim, os resultados identificaram as Notas Explicativas como o instrumento de evidenciação predominante de passivos ambientais no que diz respeito a informações sobre provisões ambientais. Percebeu-se também que, de um modo geral, que a forma de evidenciação de passivos ambientais das empresas listadas não sofreu alterações durante os anos pesquisados. E, por fim, por meio da análise da evidenciação dos passivos ambientais por setor, considerando o percentual de não evidenciação, pode-se identificar que os setores financeiros são menos transparentes em suas informações. Bem como setores de água e saneamento; consumo não cíclico; materiais básicos e utilidade pública estão entre os mais transparentes.

Palavras-chave: Evidenciação; passivos ambientais, ISE.

\section{INTRODUÇÃO}

As atividades empresariais e suas influências no meio ambiente são questões discutidas crescentemente em âmbito mundial. Com isso, a necessidade de divulgação das atividades ambientais por parte das organizações torna-se cada vez mais importante para os stakeholders. Conforme pesquisas já realizadas, esse disclosure ambiental difere de acordo coma empresa estudada, o setor e o país (NOSSA, 2002; COSTA; MARION, 2007).

As atividades empresariais e suas influências no meio ambiente são questões discutidas crescentemente em âmbito mundial. Com isso, a necessidade de divulgação das atividades ambientais por parte das organizações torna-se cada vez mais importante para os stakeholders. Conforme pesquisas já realizadas, esse disclosure ambiental difere de acordo coma empresa estudada, o setor e o país (NOSSA, 2002; COSTA; MARION, 2007).

Há ainda muita dificuldade na análise da divulgação dessas informações ambientais, seja por divulgação insuficiente ou por complexidade da informação divulgada. Segundo Mussoi e Van Bellen (2010), muitas companhias evidenciam informações menos relevantes apenas para melhorar a imagem social, enquanto informações relevantes que tratam sobre consumo de recursos e/ou emissão de poluentes, não são divulgadas, além da ausência de homogeneidade ou de linguagem simples das informações divulgadas nos relatórios.

Uma vez que a Contabilidade funciona como instrumento para fornecer informação útil para tomada de decisão e que informações ambientais são de interesse de todos os grupos de usuários, a segregação de informações ambientais torna-se necessária à medida que possibilita uma maior ênfase no acompanhamento dos resultados entre períodos e empresas, propor- 
cionando informações de maior qualidade para o processo decisório (COSTA; MARION, 2007).

No que se refere ao Passivo Ambiental, Bremenkamp, Almeida e Pereira (2011) definem esse como toda agressão contra o Meio Ambiente constituindo investimentos necessários para reabilitá-lo, por meio de multas e indenizações.

Neste sentido, a pesquisa abordará a questão da evidenciação dos passivos ambientais. Passivos ambientais são considerados obrigações de curto e longo prazo destinadas única e exclusivamente a promover investimentos em prol de ações relacionadas à extinção ou amenização dos danos causados ao meio ambiente, inclusive percentual do lucro do exercício, com destinação compulsória, direcionado a investimentos na área ambiental (MANGONARO, 2010; MELO; TINOCO; FERNANDES, 2010). Os autores afirmam que este reconhecimento e a análise do passivo ambiental são de fundamental importância para a correta avaliação da situação econômico-financeira das empresas de uma forma generalizada.

Desta forma, o estudo propõe investigar a seguinte questão: Como ocorre a evidenciação de passivos ambientais em empresas integrantes do Índice de Sustentabilidade Empresarial?

Estudos vêm apresentando resultados que demonstram ainda haver pouco disclosure relacionado a Passivos Ambientais, dentre eles, Melo, Tinoco e Fernandes (2010), que identificaram que as empresas analisadas demonstraram apenas informações positivas localizadas em Relatório da Administração. Almeida e Batista (2016) também reforçam além do pouco disclosure, não haver muita diferença nas divulgações de informações sobre passivos ambientais ao longo do tempo, mesmo com a adoção do CPC 25.

Já setores que prestam serviços de utilidade pública, como setores de energia elétrica podem apresentar um panorama diferente, uma vez que, se utilizam de recursos naturais e que, inclusive, representam um maior número de empresas classificadas no ISE. Ademais, em contraparte aos demais estudos, as pesquisas de Gubiani, Santos e Beuren (2012) alcançaram resultados diferentes, identificando presença de disclosure ambiental satisfatória. Com base no exposto, o artigo apresenta como hipóteses:

H1) A maioria das empresas evidencia seus passivos ambientais apenas em relatórios administrativos;

H2) Ao longo do período não existe diferença na forma de evidenciação dos passivos ambientais; 
H3) As empresas do setor de utilidade pública/ energia elétrica são mais transparentes na evidenciação de seus passivos ambientais. Com base no exposto, o artigo apresenta como hipóteses:

Considerando isso, a presente pesquisa tem como objetivo geral analisar o processo de evidenciação de passivos ambientais de empresas integrantes do Índice de Sustentabilidade Empresarial. Para obtenção desse objetivo, foram delineados os seguintes objetivos específicos: $i$ ) identificar o instrumento predominante utilizado na evidenciação de passivos ambientais; ii) analisar anualmente a forma de evidenciação dos passivos ambientais e iii) investigar os setores mais transparentes na evidenciação de seus passivos.

O estudo se justifica por gerar contribuições às áreas da contabilidade ambiental, por explicar utilizando as demonstrações financeiras e relatórios administrativos das empresas, se ela está reconhecendo e divulgando adequadamente os seus passivos ambientais.

A pesquisa qualifica-se quanto aos objetivos como descritiva, onde será utilizado procedimentos bibliográfico se documentais (COLLIS; HUSSEY, 2005). Com amostra composta por 34empresas listadas no ISE, divididas conforme classificação de subsetores da BM\&FBOVESPA. Os dados serão coletados a partir das Demonstrações Financeiras referentes aos exercícios de 2012, 2013 e 2014 e será utilizada análise de conteúdo com uma abordagem quantitativa.

$\mathrm{O}$ artigo encontra-se estruturado em cinco seções, sendo esta a primeira que aborda a introdução sintetizando os aspectos gerais da pesquisa; a segunda aborda a fundamentação teórica sobre disclosure ambiental e passivos ambientais; seguida pela terceira seção a respeito da metodologia utilizada para a realização do trabalho; a quarta seção apresenta os resultados encontrados na pesquisa; e encerra-se com as considerações finais.

\section{REVISÃO BIBLIOGRÁFICA}

\subsection{Teoria do Disclosure}

Disclosure pode ser considerado como uma "abertura" da empresa por meio da evidenciação de informações diante dos stakeholders, garantindo uma maior transparência corporativa a organização (GOULART, 2003).

Dye (2001) defende que a teoria do disclosure já está em um estágio considerado avançado, podendo assim ser classificada como desenvolvida. Porém Verrecchia (2001), em contraponto a essa afirmativa, considera que não existe uma teoria da divulgação ampla ou unificada, ou no mínimo alguma que se sinta "bem” para identificar como tal. Isso é, o autor 
afirma que não há ainda na literatura a demonstração de um paradigma central àrespeito do disclosure.

Nesse sentido, conforme Pagliarussi e Liberato (2011), o tema disclosure tem sido crescentemente investigado na academia, especialmente em pesquisas nas áreas de Economia e Contabilidade. Primeiramente com o full disclosure, ou divulgação plena, iniciada nos estudos de Grossman e Hart (1980), onde eles consideram essa forma de divulgar uma estratégia ótima, por prezar que as empresas disponibilizem todas as informações necessárias para que seus stakeholders tomem decisões, o que, segundo os autores, é indicado, sobretudo, quando ocorre do comprador do ativo considerar qualquer limitação de informação feita pelo vendedor desfavorável para que haja a aquisição do bem. Desta forma, Dye (1986) apresentou a estratégia do disclosure parcial que demonstrou que a divulgação parcial é ótima para o vendedor, pois a divulgação de informações proprietárias tende a reduziro valor futuro do ativo.

Segundo Bueno (1999) essa divulgação de informações, não necessariamente deve ser legal ou formal (enforced), ela também pode ser voluntária ou informal (voluntary), que referese a não obrigatoriedade legal de disponibilizar certas informações determinadas pela companhia no transcorrer de qualquer exercício.

Avelino (2013) ressalta que mais que uma divulgação de informações, para que uma empresa consiga atingir a transparência adequada, é necessária a evidenciação de informações qualitativas e quantitativas que permitam aos usuários formar uma compreensão das atividades desenvolvidas e dos seus riscos, observando aspectos de tempestividade, detalhamento e relevância.

Neste sentido da necessidade do disclosure por parte das empresas e considerando as evoluções tecnológicas, econômicas e sociais, bem como, a criação de novos produtos e consumidores cada vez mais conscientes e exigentes, surgiu-se a preocupação ambiental. Desta maneira, Gubiani, Santos e Beuren (2012) afirmam que com o aparecimento dos problemas ambientais, divulgados por cientistas e pela mídia em um âmbito mundial, a questão da preservação ambiental tornou-se uma preocupação geral, desde governo, empresas até aos cidadãos e a sociedade passou a repelir aqueles que provocam danos ambientais. Ainda conforme os autores citados, a partir dessas transformações ocorridas, nota-se que se tornou constante a busca por maior disclosure ambiental, boas práticas de governança corporativa e comportamento moral e ético por parte das organizações, sobretudo referente às informações de caráter ambiental.

Braga, Oliveira e Salotti (2009) afirmam que há uma crescente evolução no volume de informações ambientais divulgadas pelas empresas. Segundo os autores, no Brasil não existem 
leis específicas para que haja essa evidenciação, apenas algumas recomendações para a divulgação ambiental, como o Parecer de Orientação n. ${ }^{\circ}$ 15/87 da Comissão de Valores Mobiliários (CVM), a Norma e Procedimento de Auditoria n. ${ }^{\circ} 11$ do Instituto dos Auditores Independentes do Brasil (IBRACON) a Resolução n. ${ }^{\circ}$ 1.003/04 do Conselho Federal de Contabilidade (CFC) que aprova a Norma Brasileira de Contabilidade Técnica n. ${ }^{\circ} 15$.

Rover et al. (2008) ressaltam que, apesar do Brasil não dispor de leis específicas sobre disclosure ambiental, as empresas podem também evidenciar informações negativas de maneira voluntária quando acreditarem que serão punidas pelos usuários externos caso não as divulguem. Porém, conforme ressalta Nossa (2002), geralmente no disclosure voluntário é divulgado somente o que a organização tem de bom.

Nossa (2002) afirma que o que tem entusiasmado as organizações a praticarem esse disclosure ambiental de forma voluntária são os múltiplos prêmios e o ranking de relatórios ambientais instituídos por vários órgãos ambientais e outros índices. Segundo o autor um ponto considerado positivo derivado desses prêmios é que eles costumam despertar a atenção da mídia e promover um incentivo maio para adoção dos consumidores pelas empresas preocupadas com as questões ambientais. $\mathrm{O}$ autor afirma que um outro fato relevante que faz com que as organizações divulguem suas informações ambientais voluntariamente é a pressão que elas sofrem dos stakeholders, principalmente se a empresa atua em uma atividade considerada potencialmente poluidora. E por fim, outra influência para o disclosure voluntário da empresa vem dos próprios competidores das companhias, pois ao verificar que os seus competidores estão emitindo relatório ambiental, comumente a organização opta por evidenciar suas informações com o receio de que, se deixar de fazê-lo, isso possa transformar-se em uma desvantagem competitiva aos olhos dos stakeholders.

Tinoco e Kraemer (2008) acrescentam que as empresas têm demonstrado sua implicação com questões ambientais, através da elaboração de Relatórios de Sustentabilidade, também chamados de Balanço Social; ou por relatórios da administração em anexo aos balanços patrimoniais, demonstrando mais detalhadamente o seu desempenho ambiental.

Melo, Tinoco e Fernandes (2010) afirmam que o disclosure ambiental de uma organização depende da maneira como seus gestores lidam com a questão da responsabilidade ambiental. Segundos os autores, o intuito verdadeiro das empresas que divulgam seu desempenho ambiental é de maximizar recursos, pois seus relatórios ambientais destinam-se especialmente aos acionistas e proprietários, com o objetivo de fornecer a estas informações relativas às questões ambientais que podem simular de maneira positiva ou negativa os resultados empresarias no presente e em períodos futuros. 
Quanto à maneira de evidenciação das informações ambientais, Costa e Marion (2007) afirmam que a divulgação segregada das informações ambientais pode ser avaliada como um dos reforços da contabilidade para a proteção e do meio ambiente. Eles destacam que os ativos ambientais devem apresentar controle, divulgação e classificação nos grupos dos Ativos do Balanço Patrimonial. Já quanto os passivos ambientais, também devem ser explanados de forma segregada, em subgrupos específicos com a utilização das notas explicativas para especificar a natureza e os valores dos passivos ambientais. Os custos ambientais, também, devem ser considerados de maneira separada na Demonstração do Resultado do Exercício (DRE), devendo os mais importantes serem discriminados por natureza nas notas explicativas.

Dentro deste sentido da evidenciação das informações ambientais, na próxima subseção será destacado a questão dos passivos ambientais, o que são, suas peculiaridades, bem como, suas formas de divulgação mais comuns no Brasil.

\subsection{Passivos ambientais}

Passivos são sacrifícios futuros prováveis de benefícios econômicos resultantes de obrigações presentes (legais ou implícitas) e devem ser reconhecidos quando forem mensuráveis, relevantes e precisos (HENDRIKSEN; VAN BREDA, 1999; RIBEIRO FILHO; LOPES; PEDERNEIRAS, 2009).

Dentro desse conceito mais amplo, o passivo ambiental tem sido conceituadocomo toda obrigação contraída voluntária ou involuntariamente destinada à aplicação em ações de controle, preservação e recuperação do meio ambiente, tendo em contrapartida o registro de um ativo ambiental ou de um custo ambiental (FERREIRA; BUFFONI, 2006; MELO; TINOCO; FERNANDES, 2010; FERNANDES; SANTIAGO; PEIXOTO, 2012).

Nesse mesmo contexto, as dívidas ambientais das empresas representam os danos causados ao meio ambiente, representando, assim, a obrigação, a responsabilidade social das empresas com os aspectos ambientais (MANGONARO, 2010). Vellani (2008), Uehara e Tavares (2014) e Paiva (2006) corroboram que esses passivos podem surgir quando a empresa tem obrigação de prevenir, reduzir ou retificar, remediar ou proteger quanto a um dano ecológico por causa de uma obrigação legal, contratual, política, voluntária ou estratégica, tratando-se, portanto, de gastos incorridos em atividades que visam ao equilíbrio dos ecossistemas afetados pelo negócio da empresa ou pela restauração por conta da degradação do meio ambiente, como por exemplo, aquisição de ativos para contenção de impactos 
ambientais ou de insumos que reduzam produção de resíduos tóxicos ou ainda gastos para compensação de danos.

Para Vellani (2008) o passivo ambiental pode conter informações sobre o valor dos esforços das empresas em direção à sustentabilidade empresarial. Uma de suas funções pode ser a informação sobre o valora pagar relacionado ao impacto negativo de seus resíduos sobre os ecossistemas que geram multas, ou sobre gastos envolvidos com a manutenção de atividades que visem à sustentabilidade empresarial.

Os passivos ambientais ficaram amplamente conhecidos por uma conotação mais negativa, ou seja, as empresas que o possuem agrediram ou violaram significativamente o meio ambiente e, dessa forma, geraram pagamentos de vultosas quantias a título de indenização, penalidades e multas a terceiros e para a recuperação de áreas danificadas. Contudo, não possuem apenas aspectos negativos, pois podem advir de atitudes responsáveis como as decorrentes da manutenção de sistema de gerenciamento ambiental, inerentes à manutenção normal do processo operacional da empresa, voltados para a sustentabilidade. (MANGONARO, 2010; MELO; TINOCO; FERNANDES, 2010; LIMA FILHO; BRUNI; GOMES, 2013).

Não é necessário que o valor da obrigação seja conhecido com certeza, bastando que o sacrifício futuro seja provável e sem liberdade para evitá-lo (HENDRIKSEN; VAN BREDA, 1999). Porém, Ferreira e Bufoni (2006) afirmam que por não reconhecerem diretrizes seguras para o registro dos passivos ambientais muitas empresas subestimam seus valores ou simplesmente não o registram. A causa dessa omissão é a falta de conhecimento, conscientização, legislação, tecnologia ou interesse por parte dos gestores e contadores (PAIVA, 2006; LIMA FILHO; BRUNI; GOMES, 2013).

Os momentos para o reconhecimento dos passivos ambientais podem ser classificados em três categorias: primeiro com a possibilidade de reconhecer o evento antes do impacto; segundo, no momento em que a empresa percebe a causa do dano, ou seja, na ocorrência do impacto e terceiro, quando os efeitos do impacto são sentidos pela empresa e comunidade, isto é, a possibilidade de reconhecer o passivo após a ocorrência do impacto. Segundo o postulado do conservadorismo, a adoção de um espírito de precaução por parte do contador é obrigatória, devendo, portanto reconhecer antecipadamente a ocorrência do impacto (FERNANDES; SANTIAGO; PEIXOTO, 2012).

Conforme Tinoco e Kraemer (2008) há quatro tipos de obrigações decorrentes do passivo ambiental: 
Legais: quando a entidade tem uma obrigação presente legal consequente de um evento passado pelo uso do meio ambiente (água, solo, ar, etc.) ou geração de resíduos tóxicos. Essa obrigação legal surge de um contrato, legislação ou outro instrumento de lei.

Implícitas: são as a que surgem quando uma entidade, por meio de práticas do passado, políticas divulgadas ou declarações feitas, cria uma expectativa válida frente a terceiros e, por conta disso, assume um compromisso.

Construtivas: são aquelas que a empresa propõe-se a cumprir espontaneamente, excedendo as exigências legais. Podem ocorrer quando a empresa estiver preocupada com sua reputação na comunidade em geral ou quando está consciente de sua responsabilidade social, portanto usa os meios para proporcionar o bem estar ambiental da comunidade.

Justas: são aquelas que refletem a consciência de responsabilidade social, ou seja, a empresa cumpre em razão de fatos éticos e morais.

O quadro 1 apresenta sugestões de contas que devem constar no Balanço Patrimonial referente aos passivos ambientais:

Quadro 1 - Sugestão de contas de passivos ambientais

\begin{tabular}{|c|c|}
\hline CONTAS & COMENTÁRIOS \\
\hline $\begin{array}{ll} & \text { Fornecedores certificados } \\
\text { ambientalmente } \\
\text { - } & \text { Fornecedores não } \\
\text { certificados ambientalmente }\end{array}$ & $\begin{array}{l}\text { Permite identificar como a empresa } \\
\text { se relaciona ambientalmente com } \\
\text { seus fornecedores. }\end{array}$ \\
\hline $\begin{array}{l}\text { Provisão para danos } \\
\text { ambientais ocorridos (curto } \\
\text { e longo prazos). }\end{array}$ & $\begin{array}{l}\text { Reconhecimento que a empresa } \\
\text { pagará uma obrigação de origem } \\
\text { ambiental decorrente de um fato já } \\
\text { ocorrido. }\end{array}$ \\
\hline $\begin{array}{l}\text { - Reserva para contingências } \\
\text { ambientais. (Patrimônio } \\
\text { Líquido) }\end{array}$ & $\begin{array}{l}\text { Reconhecimento que a empresa } \\
\text { espera a ocorrência de um evento } \\
\text { futuro relativo à questão ambiental, } \\
\text { que se ocorrer implicará em efeito } \\
\text { negativo em seus resultados, } \\
\text { reservando parte de seus lucros para } \\
\text { atendimento desta futura obrigação. }\end{array}$ \\
\hline
\end{tabular}

Fonte -Adaptado de Coelho e Lins (2010).

Coelho e Lins (2010) enfatizam que a diferença entre provisão para danos ambientais e reserva para contingências ambientais está no fato gerador, pois no primeiro caso o fato já ocorreu, devendo ser reconhecida a despesa no período, enquanto no segundo caso trata-se da possibilidade de ocorrência, portanto a empresa reserva antecipadamente parte do seu lucro para atender a contingência, caso ocorra.

Ferreira (2011) apresenta outro elencado de contas que podem ser utilizadas, fundamentando-se no CPC 25 e IAS 37, dentre as quais se encontram: meio ambiente a recuperar; indenizações por doenças causadas; multas prováveis; aposentadorias precoces; compensações diversas; contingências de impactos causados na água; no solo ou no ar. Essas classificações devem estar de acordo com o modelo de gestão ambiental da empresa, devendo ser hierarquicamente elencadas conforme a relevância de cada conta. 
Conforme já ressaltado, no Brasil, a NBC T 15 (CFC, 2004), bem como o CPC 25 estabelecem procedimentos que não obrigam, mas que orientam a evidenciação dos passivos e das contingências ambientais. O CPC 25 normatiza sobre provisões e passivos contigentes, que representam os passivos que apresentam incertezas sobre o prazo ou valor do futuro desembolso. Almeida e Batista (2016) afirmam que, no contexto ambiental, esses passivos contingentes e provisões poderiam ser reconhecidos conforme às necessidades de preservar, proteger e recuperar o meio ambiente, de modo a permitir a compatibilidade entre este e o desenvolvimento econômico, ou em decorrência de uma conduta inadequada em relação a estas questões. Já a NBC T 15 institui a demonstração de natureza social e ambiental, devendo divulgar entre outros aspectos, investimentos, gastos com preservação e recuperação de danos ambientais, multas e indenizações e passivos e contingências ambientais (BREMENKAMP; ALMEIDA; PEREIRA, 2011).

Em suma, os conjuntos de normas existentes sugerem e estimulam a divulgação dos passivos ambientais, tendo em vista que toda atividade econômica causa algum impacto no ecossistema no qual está inserida a empresa. Ferreira (2011) sugere para os 7 relatórios contábeis, a inclusão do registro dos passivos e provisões, das reservas para catástrofes e evidenciar passivos contingentes.

A contabilidade como uma ciência dos negócios, pode evoluir para organizar uma estrutura, uma lógica, um padrão nos sistemas de informação das empresas com o intuito de fornecer informações sobre os passivos ambientais (VELLANI, 2008). A evidenciação das informações ambientais, relacionamento entre empresa e meio ambiente, bem como seus efeitos também fazem parte da função da Contabilidade Ambiental no provimento de informações aos seus diversos usuários (PAIVA, 2006; UEHARA; TAVARES, 2014).

Ressalta-se que o passivo ambiental funciona como um elemento de decisão no sentido de identificar, avaliar e quantificar posições, custos e gastos ambientais potenciais que precisam ser atendidos a curto, médio e longo prazo (MANGONARO, 2010). A falta de transparência dessas informações pode resultar em tomadas de decisões equivocadas, baseadas em números errados (VELLANI, 2008). Uehara e Tavares (2014) consideram fundamentalmente importantes o reconhecimento do passivo ambiental, para obter uma correta avaliação econômico-financeira da empresa no presente e no futuro. Quando as empresas possuem passivos ambientais e estes não se encontram identificados, pode comprometer sua manutenção e provocar grande prejuízo aos demais envolvidos, pois estes não terão subsídios para uma correta e real avaliação da situação da empresa e, desta forma,não poderão julgar a viabilidade de fazerem investimentos nela (BERTOLI; RIBEIRO, 2006). 
Lima Filho, Bruni e Gomes (2013) enfatizam que o passivo ambiental era considerado um redutor de lucros nas atividades empresariais, mas ultimamente tornou-se um diferencial competitivo que está sendo incorporado à cultura empresarial, pois seu reconhecimento evidencia uma preocupação importante da atividade empresarial e inter-relação com o meio ambiente, podendo afetar seriamente a continuidade da empresa. Os passivos ambientais podem ser utilizados para passar uma imagem melhor da responsabilidade social e ética das empresas.

Diversos estudos tratam da importância dos passivos ambientais, porém a grande maioria identificou que não é dada a devida importância para esses registros e divulgações tanto por parte de empresas, contadores e acadêmicos (BERTOLI; RIBEIRO, 2006; MELO; TINOCO; FERNANDES, 2010; FERNANDES; SANTIAGO; PEIXOTO, 2012; LIMA FILHO; BRUNI; GOMES, 2013; UEHARA; TAVARES, 2014).

Melo, Tinoco e Fernandes (2010), partiram de estudos que ao analisar demonstrações financeiras de grandes empresas divulgadas e com ações negociadas em bolsa de valores observou a ausência de informações sobre o passivo ambiental na contabilidade dessas entidades. O que se viu nessas divulgações foram apenas informações de forma sintética sobre algumas ações de minimização de impacto ambiental,informações sobre os investimentos realizados na área ambiental, ou seja, informações declarativas (informação qualitativa expressa em termos descritivos), do tipo positiva, localizadas no Relatório da Administração e não auditadas, contrárias à Teoria do Disclosure e confirmaram que são poucas as empresas que registram estes passivos de forma correta e completa.

A próxima seção destina-se aos procedimentos metodológicos deste estudo, a partir dos quais será analisada a evidenciação dos passivos ambientais das organizações listadas no Índice de Sustentabilidade Empresarial - ISE.

\section{METODOLOGIA}

Quanto ao objetivo da pesquisa, qualifica-se como descritiva adotando procedimentos bibliográficos e documentais (COLLIS; HUSSEY, 2005). A apreciação do estudo se dá por meio da técnica de análise de conteúdo considerada "uma técnica de pesquisa que trabalha com a palavra, permitindo de forma prática e objetiva para produzir inferências do conteúdo da comunicação" (CAREGNATO; MUTTI, 2010).

A população é composta por 47 empresas que estão listadas no Índice de Sustentabilidade Empresarial (ISE) para os anos de 2012, 2013 e 2014, tendo em vista que a partir de 2012 as informações desse índice passaram a contar com um processo auditoria, 
tornando-o mais confiável e considerando que esse índice tende a estimular a transparência e o desempenho socioambiental das organizações nele listadas (ISE, 2014). Por conta da análise anual da forma de evidenciação dos passivos ambientais, foram consideradas apenas as empresas que estão listadas nos três anos citados de forma concomitante, tendo, portanto, a amostra reduzida para 34 empresas.

A análise realiza-se em dados secundários a partir das Demonstrações Financeiras referentes aos exercícios anteriores a cada ano do ISE, isto é, de 2011, 2012 e 2013, obtidos através do site da BM\&FBOVESPA. Dentro desse contexto, serão avaliados o Balanço Patrimonial, as Notas Explicativas e o Relatório da Administração, que segundo a literatura estudada são as formas mais empregadas na evidenciação do passivo ambiental pelas companhias.

A Tabela 1 apresenta a quantidade de empresas divididas conforme classificação dos setores econômicos da BM\&FBOVESPA.

Tabela 1-Quantidades de empresas por subsetor BM\&FBovespa

\section{Setor Bovespa}

\section{Quantidade}

\begin{tabular}{lc}
\hline Utilidade Pública / Energia Elétrica & 11 \\
Financeiro e Outros & 7 \\
Materiais Básicos(Químicos; Madeira e Papel; Siderurgia e Metalurgia; Mineração) & 7 \\
Consumo não Cíclico(Alimentos Processados; Saúde; Produtos de Uso Pessoal e limpeza) & 2 \\
Construção e Transporte & 3 \\
Água e Saneamento & 2 \\
Telecomunicações & 2 \\
\hline Total & 34
\end{tabular}
Fonte-Elaborado pelos autores.

Por meio da técnica de análise de conteúdo será utilizada a abordagem quantitativa, pois os dados serão avaliados por meio da frequência das características que se repetem no texto (CAREGNATO; MUTTI, 2010). A partir dos relatórios das empresas selecionadas, as informações no tocante ao passivo ambiental foram categorizadas e verificadas de acordo com os termos adaptados da sugestão de Coelho e Lins (2010), referentes aos itens que deveriam ser divulgados, conforme abaixo:

1) Informações referentes a fornecedores certificados ambientalmente;

2) Provisões ambientais;

3) Reservas para contingências ambientais;

4) Outras informações relacionadas a passivos ambientais. 
Desta maneira, na próxima subseção será explanada a análise dos resultados e o confronto daquilo que foi obtido com as hipóteses lançadas no início do artigo.

\section{ANÁLISE DOS RESULTADOS}

Conforme primeiro objetivo específico, a Tabela 2 apresenta os instrumentos predominantes utilizados na evidenciação de passivos ambientais:

Tabela2-Instrumentos predominantes de evidenciação de passivos ambientais

\begin{tabular}{|c|c|c|c|c|c|c|c|c|}
\hline \multirow[t]{2}{*}{$\begin{array}{l}\text { Instrumento de } \\
\text { Evidenciação }\end{array}$} & \multicolumn{8}{|c|}{$\begin{array}{l}\text { NÚMERO DE EMPRESAS(*) QUE EVIDENCIARAM CONFORME } \\
\text { CATEGORIAS DE INFORMAÇÕES DE PASSIVOS AMBIENTAIS(**) }\end{array}$} \\
\hline & 1 & $\%$ & 2 & $\%$ & 3 & $\%$ & 4 & $\%$ \\
\hline Balanço Patrimonial & 0 & $0 \%$ & 5 & $15 \%$ & 0 & $0 \%$ & 1 & $3 \%$ \\
\hline Notas Explicativas & 0 & $0 \%$ & 17 & $50 \%$ & 0 & $0 \%$ & 1 & $3 \%$ \\
\hline Relatório da Administração & 9 & $26 \%$ & 2 & $6 \%$ & 0 & $0 \%$ & 1 & $3 \%$ \\
\hline Não evidenciaram & 25 & $74 \%$ & 16 & $47 \%$ & 34 & $100 \%$ & 33 & $97 \%$ \\
\hline TOTAL DE EMPRESAS & 34 & & 34 & & 34 & & 34 & \\
\hline
\end{tabular}

(*) Uma mesma empresa pode ter evidenciado em mais de um instrumento.

(**) Categorias de informações de passivos ambientais:

1) Informações referentes a fornecedores certificados ambientalmente;

2) Provisões ambientais;

3) Reservas para contingências ambientais;

4) Outras informações relacionadas a passivos ambientais.

Por meio da análise de conteúdo, identificam-se as Notas Explicativas comoo instrumento de evidenciação predominante de passivos ambientais, correspondendo a $50 \%$ do total de empresas no que diz respeito a informações sobre provisões ambientais. Tal resultado implica na recusa da hipótese 1, tendo em vista que o Relatório da Administração foca em segundo lugar, com $26 \%$ das empresas evidenciando algum tipo de informação referente a fornecedores certificados ambientalmente. Ressalta-se que, em sua maioria, as empresas não evidenciaram informações referentes aos passivos ambientais, bem como nenhuma empresa evidenciou informações sobre reservas para contingências ambientais.

Em atendimento ao segundo objetivo específico, a Tabela 3 representa um comparativo anual da forma de evidenciação dos passivos ambientais.

Tabela3-Comparativo anual da evidenciação de passivos ambientais

\begin{tabular}{|c|c|c|c|c|c|c|}
\hline \multirow{2}{*}{$\begin{array}{c}\text { CATEGORIAS DE } \\
\text { INFORMAÇÕES DE } \\
\text { PASSIVOS } \\
\text { AMBIENTAIS }(* *)\end{array}$} & \multicolumn{6}{|c|}{ NÚMERO DE EMPRESAS (*) } \\
\hline & 2013 & $\%$ & 2012 & $\%$ & 2011 & $\%$ \\
\hline
\end{tabular}




\begin{tabular}{crrrrrr}
1 & 7 & $21 \%$ & 8 & $24 \%$ & 7 & $21 \%$ \\
2 & 18 & $53 \%$ & 18 & $53 \%$ & 18 & $53 \%$ \\
3 & 0 & $0 \%$ & 0 & $0 \%$ & 0 & $0 \%$ \\
4 & 1 & $3 \%$ & 1 & $3 \%$ & 1 & $3 \%$ \\
Não evidenciaram & 14 & $41 \%$ & 14 & $41 \%$ & 14 & $41 \%$ \\
\hline TOTAL DE EMPRESAS & $\mathbf{3 4}$ & $\mathbf{3 4}$ & $\mathbf{3 4}$ & \\
\hline \multicolumn{7}{c}{ Fonte -Dados da pesquisa. }
\end{tabular}

(*) Uma mesma empresa pode ter evidenciado mais de uma categoria de informação.

(**) Categorias de informações de passivos ambientais:

1) Informações referentes a fornecedores certificados ambientalmente;

2) Provisões ambientais;

3) Reservas para contingências ambientais;

4) Outras informações relacionadas a passivos ambientais.

Percebe-se, de um modo geral, que a evidenciação de passivos ambientais das empresas listadas não sofreu alterações durante os anos pesquisados, de modo a confirmar a hipótese 2. Para atender o terceiro objetivo específico, a Tabela 4 demonstra a evidenciação dos passivos ambientais por setor econômico

Tabela4-Evidenciação de passivos ambientais por setor

\begin{tabular}{|c|c|c|c|c|c|c|c|c|c|c|c|}
\hline \multirow[t]{2}{*}{$\begin{array}{c}\text { SETOR } \\
\text { ECONÔMICO }\end{array}$} & \multirow{2}{*}{$\begin{array}{c}\text { TOTAL DE } \\
\text { EMPRESAS }\end{array}$} & \multicolumn{8}{|c|}{$\begin{array}{l}\text { NÚMERO DE EMPRESAS (*) QUE } \\
\text { EVIDENCIARAM INFORMAÇÕES } \\
\text { REFERENTES A PASSIVOS } \\
\text { AMBIENTAIS (**) }\end{array}$} & \multirow{2}{*}{$\begin{array}{l}\text { NÃO } \\
\text { EVIDEN- } \\
\text { CIARAM }\end{array}$} & \multirow[b]{2}{*}{$\%$} \\
\hline & & 1 & $\%$ & 2 & $\%$ & 3 & $\%$ & 4 & $\%$ & & \\
\hline Água e Saneamento & 2 & 0 & $0 \%$ & 2 & $100 \%$ & 0 & $0 \%$ & 0 & $0 \%$ & 0 & $0 \%$ \\
\hline Construção e Transporte & 3 & 1 & $33 \%$ & 1 & $33 \%$ & 0 & $0 \%$ & 0 & $0 \%$ & 1 & $33 \%$ \\
\hline Consumo não Cíclico & 2 & 1 & $50 \%$ & 1 & $50 \%$ & 0 & $0 \%$ & 0 & $0 \%$ & 0 & $0 \%$ \\
\hline Financeiro e Outros & 7 & 0 & $0 \%$ & 0 & $0 \%$ & 0 & $0 \%$ & 0 & $0 \%$ & 7 & $100 \%$ \\
\hline Materiais Básicos & 7 & 2 & $29 \%$ & 6 & $86 \%$ & 0 & $0 \%$ & 0 & $0 \%$ & 1 & $14 \%$ \\
\hline Telecomunicações & 2 & 0 & $0 \%$ & 1 & $50 \%$ & 0 & $0 \%$ & 0 & $0 \%$ & 1 & $50 \%$ \\
\hline Utilidade Pública & 11 & 5 & $45 \%$ & 7 & $64 \%$ & 0 & $0 \%$ & 1 & $9 \%$ & 3 & $27 \%$ \\
\hline
\end{tabular}

(*) Uma mesma empresa pode ter evidenciado mais de uma categoria de informação.

(**) Categorias de informações de passivos ambientais:

1) Informações referentes a fornecedores certificados ambientalmente;

2) Provisões ambientais;

3) Reservas para contingências ambientais;

4) Outras informações relacionadas a passivos ambientais.

Por meio da análise da evidenciação dos passivos ambientais, por setor, considerando o percentual de não evidenciação, pode-se identificar que os setores financeiros são menos transparentes em suas informações. Bem como setores de água e saneamento; consumo não cíclico; materiais básicos e utilidade pública estão entre os mais transparentes, confirmando parcialmente a hipótese 3 . 
Ao analisar o processo de evidenciação dos passivos ambientais de empresas integrantes do ISE, percebe-se que ainda há setores que não evidenciam passivos ambientais, e ainda ausência de categorias de informações evidenciadas, corroborando com os estudos de Bertoli e Ribeiro (2006); Melo; Tinoco e Fernandes (2010); Fernandes; Santiago e Peixoto (2012); Lima Filho; Bruni e Gomes (2013); e Uehara e Tavares (2014).

\section{CONCLUSÃO}

Conforme a literatura estudada, verificou-se que a evidenciação dos passivos ambientais é uma questão importante para a correta avaliação da situação econômicofinanceira das organizações de uma forma generalizada. A partir deste contexto, a questão crítica que orientou este estudo foi: Como ocorre a evidenciação de passivos ambientais em empresas integrantes do Índice de Sustentabilidade Empresarial - ISE?

Para tanto, o objetivo geral da pesquisa consistiu em analisar o processo de evidenciação de passivos ambientais de empresas integrantes do Índice de Sustentabilidade Empresarial - ISE. A pesquisa empírica analisou as demonstrações financeiras, notas explicativas e relatórios administrativos divulgados por 34 empresas listadas no ISE para os anos de 2012, 2013 e 2014, onde, a partir dos dados coletados, foram feitas inferências quanto os objetivos específicos.

Com relação ao primeiro objetivo específico, encontrou-se que $50 \%$ das provisões para os passivos ambientais estão expostos nas Notas Explicativas. Desta forma, H1 que argumenta que a maioria das empresas evidencia seus passivos ambientais apenas em relatórios administrativos, foi rejeitada.

À respeito do segundo objetivo específico, foi exposto que a evidenciação de passivos ambientais das empresas listadas não sofreu alterações durante os anos pesquisados, o que confirmou a H2, que diz que não existe diferença anual na forma de evidenciação dos passivos ambientais.

Já quanto ao terceiro objetivo específico, verificou-se que os setores financeiros são menos transparentes em suas informações. E que os setores de água e saneamento; consumo não cíclico; materiais básicos e utilidade pública estão entre os mais transparentes, confirmando parcialmente $\mathrm{H} 3$, que diz que as empresas do setor de utilidade pública/ energia elétrica são mais transparentes na evidenciação de seus passivos ambientais.

Portanto, os resultados indicaram que ainda existem setores que não evidenciam seus passivos ambientais de forma correta, corroborando com os estudos de Bertoli e Ribeiro 
(2006); Melo; Tinoco e Fernandes (2010); Fernandes; Santiago e Peixoto (2012); Lima Filho; Bruni e Gomes (2013); e Uehara e Tavares (2014).

Cabe enfatizar que o estudo apresenta limitações em virtude da segmentação da amostra às empresas listadas no ISE de 2012, 2013 e 2014, que apesar de permitir a comparação entre setores, eles não devem ser generalizados.

E por fim, recomenda-se a ampliação dos estudos sobre evidenciação de passivos ambientais considerando quantidades maiores de empresas, comparando-as entre listadas e não listadas no ISE e considerando níveis poluidores de alto, médio e baixo impacto.

\title{
DISCLOSURE ENVIRONMENTAL LIABILITIES: A STUDY WITH COMPANIES MEMBERS OF ISE
}

\begin{abstract}
The study aims to analyze the process of disclosure of environmental liabilities of members of the Corporate Sustainability Index companies - ISE. The research is justified by generating contributions to the areas of environmental accounting and demonstrates that the organizations listed in this index are adequately demonstrating their environmental liabilities. A descriptive research, quantitative in nature, through the technique of content analysis of secondary data, the financial statements, management reports and notes. The sample consisted of 34 companies listed on the ISE for the years 2012, 2013 and 2014, based on secondary from the Financial Statements for the year prior to each ISE exercises, obtained through the BM\&FBOVESPA site data. Thus, we assessed the Balance Sheet, the Notes and the Management Report, which according to the literature studied are the ways most employed in disclosure of environmental liabilities by companies. The results identified the Notes as the predominant instrument of disclosure of environmental liabilities with respect to information on environmental provisions. We also noticed that, in general, that the form of disclosure of environmental liabilities of listed companies has not changed over the years surveyed. Finally, by analyzing the disclosure of environmental liabilities by sector, considering the percentage of non-disclosure, one can identify that the financial sectors are less transparent in their information. And water and sanitation sectors; consumer staples; basic materials and utilities are among the most transparent.
\end{abstract}

Keywords: Disclosure; environmental liabilities; ISE.

\section{REFERÊNCIAS}

ALMEIDA, Karla Katiuscia Nóbrega de; BATISTA, Fabiano Ferreira. Provisões Contingentes Ambientais e seus Reflexos no Endividamento das Empresas de Alto Impacto Ambiental Após Adoção do CPC 25. Sociedade, Contabilidade e Gestão, v. 11, n. 1, 2016.

AVELINO, B. C. Características explicativas do nível de disclosure voluntário de municípios do estado de Minas Gerais: uma abordagem sob a ótica da teoria da divulgação. 2013. 176 f. Dissertação (Mestrado em Ciências Contábeis). Centro de Pós-Graduação e Pesquisas em Contabilidade e Controladoria da Universidade Federal de Minas Gerais, Minas Gerais. 2013. 
BERTOLI, A. L.; RIBEIRO, M. de S. Passivo ambiental: estudo de caso da Petróleo Brasileiro S.A -Petrobrás: a repercussão ambiental nas demonstrações contábeis, em consequência dos acidentes ocorridos. RAC - Revista de Administração Contemporânea, v. 10, n. 2, Abr./Jun. p. 117-136, 2006.

BRAGA, J. P.; OLIVEIRA, J. R. S.; SALOTTI, B. M. Determinantes do nível de divulgação ambiental nas demonstrações contábeis de empresas brasileiras. In: CONGRESSO USP DE CONTROLADORIA E CONTABILIDADE, 2009, São Paulo. Anais... São Paulo, 2009.

BREMENKAMP, Fabiano Helmer; ALMEIDA, José Elias Feres de; PEREIRA, Maria Mariete Aragão Melo. Análise do disclosure relacionado a acidentes ambientais da Petrobras após a Lei nº 11.638/07. Sociedade, Contabilidade e Gestão, v. 6, n. 3, 2012.

BUENO, A. F. Problemas de disclosure no Brasil: o caso das empresas com ações no exterior. Caderno de Estudos, v. 1, n. 20, Jan/Abr. p. 1- 13, 1999.

CAREGNATO, R. C. A; MUTTI, R. Pesquisa qualitativa: análise de discurso versus análise de conteúdo. Texto Contexto Enferm, v. 15,n.4, Out/Dez, p. 679-684, 2006.

CFC - Conselho Federal de Contabilidade. NBCT-15, Resolução nº ${ }^{\circ} 1.003$, de 19 de agosto de 2004. Dispõe sobre Informações de Natureza Social e Ambiental. Brasília, 2004.

COELHO, C. U. F.; LINS, L. S. Teoria da Contabilidade: abordagem contextual, histórica e gerencial. São Paulo: Atlas, 2010.

COLLIS, J.; HUSSEY, R. Pesquisa em administração: um guia prático para alunos de graduação e pós-graduação. 2 ed. Porto Alegre: Bookman, 2005.

COSTA, R. S.; MARION, J. C. A uniformidade na evidenciação das informações ambientais. Revista Contabilidade \& Finanças, v. 43, p. 20-33, jan./abr. 2007.

DYE, R. A. Proprietary and nonproprietary disclosures. The Journal of Business, Chicago, v. 59, n. 2, p. 331-366, Apr. 1986.

DYE, R A. An evaluation of "essays on disclosure" and the disclosure literature in accounting. Journal of Accounting and Economics . v. 32, p. 181-235, 2001.

FERNANDES, S. M.; SANTIAGO, W. de P.; PEIXOTO, F. M. Passivo ambiental: um levantamento em empresas localizadas no município de Montes Claros/MG. In: XV SEMINÁRIOS EM ADMINISTRAÇÃO, 2012, São Paulo. Anais...São Paulo, 2012. FERREIRA, A. C. S. Contabilidade Ambiental: uma informação para o desenvolvimento sustentável. 3 ed. São Paulo: Atlas, 2011. 
FERREIRA, A. C. de S.; BUFONI, A. L. A assimetria informacional do risco ambiental nas demonstrações financeiras: um estudo comparativo Brasil x EUA. Pensar Contábil, v. 8, n. 31, p. 1-11, 2006.

GOULART, A. M. C. Evidenciação contábil do risco de mercado por instituições financeiras no brasil. 2003. 202 f. Dissertação (Mestrado em Ciências Contábeis) Programa de Pós-Graduação em Controladoria e Contabilidade, Faculdade de Economia, Administração e Contabilidade da Universidade de São Paulo, São Paulo. 2003.

GROSSMAN, S. J.; HART, O. D. Disclosure laws and take overbids. The JournalofFinance, Cambridge, v. 35, n. 2, p. 323-334, May, 1980.

GUBIANI, C.A; SANTOS, V.; BEUREN, I. S. Disclosure ambiental das empresas de energia elétrica listadas no Índice de Sustentabilidade Empresarial (ISE). Sociedade, Contabilidade e Gestão, Rio de Janeiro, v. 7, n. 2, jul/dez , 2012.

HENDRIKSEN, E. S.; VAN BREDA, M. F. Teoria da Contabilidade. Tradução da $5^{\text {a }}$ edição americana, por Antonio Zoratto Sanvicente. São Paulo: Atlas, 1999.

ISE - ÍNDICE DE SUSTENTABILIDADE EMPRESARIAL, BM\&F BOVESPA Disponível em: < http://isebvmf.com.br/index.php?r=site/conteudo\&id=1> Acesso em 5 de junho de 2013.

LIMA FILHO, R. N.; BRUNI, A. L.; GOMES, S. M. da S. A compreensão dos estudantes sobre o conceito de passivo ambiental: um estudo nos cursos Ciências Contábeis em Salvador-BA. Revista Pensamento Contemporâneo em Administração, v. 7, n. 1, p. 108$121,2013$.

MANGONARO, J.C. Desenvolvimento sustentável: considerações acerca do desenvolvimento ecônomico versus passivo ambiental. Revista de Direito Público, Londrina, v. 5 , n. 1, p. $157-168, a b r / 2010$.

MELO, I. C. A.; TINOCO, J. E. P.; FERNANDES, M. F. Passivo Ambiental: a importância do reconhecimento, do registro contábil e da divulgação. eGesta:Revista Eletrônica de Gestão de Negócios da Universidade Católica de Santos. Santos, v. 6, n. 2, p.72-101, abrjun, 2010.

NOSSA, V. Disclosure ambiental: uma análise do conteúdo dos relatórios ambientais de empresas do setor de papel e celulose em nível internacional. 2002. 245f. Tese (Doutorado em 
Controladoria e Contabilidade) - Departamento de Contabilidade e Atuária da Faculdade de Economia, Administração e Contabilidade da Universidade de São Paulo, São Paulo. 2002.

PAGLIARUSSI, M. S.; LIBERATO, G. B. Disclosure de estratégia em relatórios anuais: uma análise de dimensões culturais, de sistema legal e de governança corporativa em empresas de quatro países. RAM - Revista de Administração Mackenzie, v. 12, n. 4, São Paulo, jul/ago. 2011.

PAIVA, P. R. de. Contabilidade ambiental: evidenciação dos gastos ambientais com transparência e focada na prevenção. 1 ed. 2 reimpr. São Paulo: Atlas, 2006.

ROVER, S.; MURCIA, F. D.; BORBA, J. A.; VICENTE, E. F. R. Divulgação de informações ambientais nas demonstrações contábeis: um estudo exploratório sobre o disclosure das empresas brasileiras pertencentes a setores de alto impacto ambiental. RCO - Revista de Contabilidade e Organizações, FEARP/USP, v. 2, n. 3, p. 53 - 72 mai./ago. 2008.

TINOCO, J. E. P; KRAEMER, M. E. P. Contabilidade e Gestão Ambiental. São Paulo: Atlas, 2011.

UEHARA, D. dos S.; TAVARES, F. C. Contabilização do passivo ambiental: estudo de caso -mineradoras da região do Alto Tietê (SP). In: $18^{\circ}$ CONGRESSO BRASILEIRO DE CONTABILIDADE, 2008, Gramado. Anais... Gramado, 2008.

VERRECCHIA, R. E. Essays on Disclosure. Journal of Accounting and Economics, n. 32, p. 97-180, jun, 2001.

VELLANI, C. L. Passivo ambiental e ecoeficiência. Revista FACEF Pesquisa, v. 11, n. 3, 2008 . 